\title{
Social Media: A New Way of Public and Political Communication in Digital Media
}

\author{
https://doi.org/10.3991/ijim.v11i6.6876 \\ Patrícia. M. F. Coelho \\ University of Santo Amaro - UNISA, Santo Amaro, Brasil \\ Pedro A. P. Correia $\left({ }^{\square}\right)$ \\ University of Madeira, Funchal, Portugal \\ pacorreia@staff.uma.pt \\ Irene Garcia Medina \\ Glasgow Caledonian University, Glasgow, UK
}

\begin{abstract}
Today, social media are the new way of public and political communication in digital marketing. Companies or organizations are no longer the exclusive owners of the relation of consumers with their products/services; instead, the survival of the organizations depends of the effective utilization of the social media. New web technologies have made it easy for anyone to create and distribute their own content. A tweet can be viewed by virtually millions of people for free, and advertisers don't have to pay publishers huge sums of money to embed their messages. More consumers are on social media than ever before, and every second a company is not engaged is a wasted opportunity [1]. Consumers trust other people to provide recommendations about products and services in a very active way and it is important to know how and why social media influence organizations. This study analyzes through a literature review the importance of public and political communication through social media and proposes a model of business for successful marketing strategies.
\end{abstract}

Keywords-Social media, public communication, political communication

\section{Introduction}

Social media is a large and still growing phenomenon which is having a huge effect on the world in which we live today. Social media is now considered to be one of the most effective and commonly used means of communicating with customers today [6]. However, we first must break down exactly what social media is. The word 'social' refers to the interaction between a person and a group, where a co-operative and interdependent relationship is formed, and the word 'media' relates to the means of communicating through platforms such as the internet or television that reach and influence a mass amount of people. Therefore, we can deduce that social media is the 
means of communication based on relationships built around online communities made possible through the internet [10].

The first social media page was created in 1994 through Geocities, however never took off on a global scale until Myspace was founded in 2003. Today, roughly $25 \%$ of the world's population use social media (1.7 billion), with the most popular websites being Facebook, Twitter and YouTube. This huge usage is furthered through statistics by [2], where she states that $71 \%$ of adults are online, and $72 \%$ of these people are also on social media [2]. Also, this phenomenon goes far beyond any stereotypes refers to the interaction between a person and a group, where a co-operative and interdependent relationship is formed, and the word 'media' relates to the means of communicating through platforms such as the internet or television that reach and influence a mass amount of people.

The participation on a massive scale of thousands of people throughout the world to the phenomenon of social media has contributed to the exponential growth of the various social networking, allowing them to achieve the critical mass necessary for the social media to become an appreciated channel of communication for many public or political organizations.

Reference [8] says that "the use of the on-line phenomenon by organizations involves developing a communication program of integrated marketing, maximizing the individual and collective contribution of all the activities of communication, defining for the virtual channels a program of communication more personnel in the field of direct and interactive marketing".

An approach to transparency and trust concentrated the whole organization, and is an integral part of the activities of management, in particular in the perception of the internal and external environment, the vision and mission, defining and implementing strategies and monitoring.

\section{Public and politic communication}

It is key for public and political communication to adapt to and understand social media properly, and as a result should utilize online tools such as Web 2.0. This kind of website allows users to communicate and connect with each other through online platforms, where the individual is totally in control of the creation of their page. Although no one exact description about this platform exists, it is widely regarded that it presents both the individual and company with many computer paradigms that challenge the norm. In response to this, to accommodate this lack of certainty on the issue where additional research is required, it is suggested by [7] that companies should stick to seven basic principles;

1. The web as a platform- illustrates the change from a predominantly Microsoft featured desktop to one which incorporates the freedom of a social media one.

2. Harnessing collective intelligence- embracing consumer connectivity and views to ensure better content.

3. Data as the next Intel inside- Increased value through using data and content to shape company decisions. 
4. The end of the software release cycle- Constantly updating data accessed through online platforms.

5. Lightweight programming models- Increased use of transparent and flexible online tools.

6. Software above the level of a single device- Where all data is available to any person at any time with a desktop or smartphone.

7. Rich user experiences- Highlights the trend for online audio and interactive content.

These different factors combined should aid the business in adapting to and utilizing social media, and although these principles are merely a glimpse into what is required for successful integration of these components, the most important factor to note is the change towards the internet becoming the most important technological platform [7].

This change in the importance of technological platforms is best seen through the shift towards digital marketing expressed by [1]. This progression has resulted in not only in difference in the public and political communication strategies employed by companies, but also the levels of engagement between parties. Previously, marketing would have been done through traditional methods such as radio broadcasts or print media, and would have employed the same push messaging to a mass amount of people in a formal and authoritative manner, and as a result would have experienced low levels of personal engagement.

Traditional marketing has since been updated to incorporate more technology and focus on niche groups through means such as e-mails and banners; however it is the shift towards social engagement through digital marketing which really emphasizes connectivity and endorses the use of social media. Here individuals are targeted through networks, blogs, and online communities, with emphasis being placed on the importance of regular dialogue in an informal manner, and targets a niche group through the technological advances available [1].

Due to this change in approach, customer's demands and expectations from companies have changed. They are no longer satisfied with the same boring adverts being sent to everyone, they want campaigns which challenge and provoke them rather than businesses which are seen to merely pander to their needs [3]. Therefore the conclusion can be drawn that public and political communication based on social media is about interacting, communicating and engaging with customers to ensure business objectives are met, and it is the strategy rather than the platform which is of the most importance.

This requirement of niche marketing and targeting each individual in a manner which is suitable to them personally has created an increasingly fragmented and diverse marketplace [3]. This has allowed for four identifiable zones of social media to be highlighted which are expressed by [10], all of which deal with different components of the platform; Social community, social publishing, social entertainment and social commerce.

The first section here of social community refers to the socializing and sharing between parties where regular dialogue is maintained to keep up to date with consumer 
tastes and trends. Social entertainment is the games, music and art offered as an additional service to customers to ensure their experience with the business is as enjoyable as possible. Social commerce deals with the customer service and retailing side of the business where online platforms are utilized to deal with any queries or complaints efficiently, and the final zone here is social publishing, which relates to the editorial and commercial side of the business [10].

\section{A new model of business}

The strategic basis for social media is based in real relationship with people, find out what is important in long-term relationship between the organization and its fans and focus on genuine relationships, honest, lasting and value to both understand who is interested in maintaining a relationship with us and is truly on and react to our presence and actions. Important are those with whom we have a relationship of proximity and interactivity that allows the exchange of views and discussions on common interests, people who actively participate with their opinion on the subject, people who compliment or criticize you because they live in this community.

The difference is about people feeling essential to the relationship. Consequently, "networking" is important when there is a real link for everyone and is a useless distraction when the real connection does not exists, although we are constantly seduced by the image of useless popularity based on the numbers, it is important to know who follows my path and what I would follow them and go after these people and get the privilege of one day be able to gain value from this relationship [9].

For companies it is important to select those who want to serve, as in off-line strategies is important to know which the group is / segment to serve. Use social media marketing requires a different attitude, it is useless to use the same "speak loud" offline, it is necessary the link between people and the organization, both followers of a common interest. Behavioral changes manifested by customers in on-line experience are more pronounced, and revealed the need to monitor this behavior as a way to effectively understand the target market at the moment.

The on-line segmentation has focused on the selection of specific population groups with homogeneous characteristics, including the origin of the visitor, who is, what products and services are more seen. Combining these variables it is possible to specify the target segments capable of responding to offers / specific messages Targeting social networks turns out to have more support elements which gave it greater accuracy, a result of the spontaneity of the people in the completion and regular updating of their profile, including records of demographic, geographic, psychographic and behavioral attitudes through their tastes and desires.

The segmentation identified with the actual characteristics of the group, provides a more solid basis for marketing actions, the marketing -mix with that audience can offers most effective results on-line than off-line, in addition to increasing channel options information and marketing communications and the resulting contribution.

The greater the match between the needs / desires of consumers in their "target" with the message of the company, the greater the importance to consumers, increasing 
their loyalty to the organization / brand and the implementation of identified opportunities.

The aim is, in a pragmatic perspective, to provide tools for analysis and decision support regarding the future implementation of the four variables of marketing mix: product, price, distribution and communication. The variable product may be considered as central in marketing strategy, considering that the pricing strategy is defined taking into account the characteristics and performance of the product, the degree of customer satisfaction and their sales volumes, the distribution strategy is strongly influenced by the characteristics of their products and consumers' purchasing behaviors associated with them, the communication strategy is formed from the features and benefits provided by the product. Nevertheless, to the level of strategy formulation, the variable product does not dominate over the other variables, because the marketing strategy involves decisions in the four variables, firms may allocate more or less importance to one (s) them, selecting those that are essential, acting as engines of development of its offer. The important thing is to formulate an offer that meets the desires and needs of the target market. The marketing communication are the means that companies have to inform and remind consumers to interact (directly or indirectly) about the products / services and brands they sell and is a way to establish a dialogue and relationships with their customers [4].

Communication has several functions, you can tell how and why the product is used, what kind of people use it, where and when you use it, consumers can know who produces under that mark and may receive an incentive to use it. It allows companies to connect their brands to people, places, events, other brands, experiences, feelings, etc.. And contribute to creating a brand image. It is why social media should be integrated into the marketing - mix strategy relevant to the marketing communications program, maximizing individual and collective contribution of all stakeholders.

In communication, there are two important objectives, first to alert the recipient of the message, the second time to win their attention. In a world saturated with information and suspicion, to achieve these objectives requires an increased effort. In an analogy economic time for individual attention is a scarce resource for excellence in developed societies in paradox with a growing supply. In this scenario brands need to make a greater effort to achieve more than a little public attention saturated by messages trying to get their attention and less tolerance for invasion of personal space [5].

People are constantly bombarded with contents of consumer marketing, but they are looking for honest interactions with real content. The most important message is one that is passed from one friend to another, which means that marketing needs to ensure that all communication is as open and honest as possible, be authentic and away from bonds that may seem unethical.

An account of the need to create, plan, feed, protect and update constantly to respond to unrest caused by social media. These information technologies (internet, mobile) made the cost of creation, production and cheap distribution of content to the receivers, which ceases to be a passive audience so as to become active participants in communication, deciding on the content and form of the message, modifying it to become co-authors. In this interactivity, the life cycle of the messages is uncontrollable, is no longer a sealed package to become a transformative content, which diffusion 
is enhanced by on-line channels. We will learn that success will depend on how we tell and how people tell us the reality [4].

It is difficult for any organization to be present in all social media effectively, therefore, should select those who may have more value in order to be able to respond appropriately to all requests. It is better to opt for one or a few channels that exist in everyone and do not communicate efficiently and effectively with the selected audience, hence the need for a strategy that defines the channels and the modus operandi for each one and do not follow or to be present just because the competition is there. Selling price is based on a strategy used by many companies in restrictive conditions of inequality and operation of multinational dimension, and therefore, its actions must involve the use of means that differentiate from the larger companies. The idea is to see who in your virtual community and how they feel their presence, who is connected to the company and make a difference by adding value beyond the physical product and price, with shares that may be based on tools provided by social media.

Human beings are naturally social; they want contact with other people in developing different public activities from social events up to sporadic coffee. In social media that need is amplified by a community that is constantly creating, sharing, collaborating, commenting, criticizing, etc.. spontaneously. Thus, it is important for the organization to show a human character to your community. Honesty, transparency, loyalty, generosity, respect are adjectives that characterize and solidify the notion of belonging to the community and the satisfaction of basic human need and that makes the difference with the competitors, differentiating it from the way the organization does and why does.

It is important that the organization fosters an attitude of belonging on the part of its target audience, a community where people interact with the organization and feel it as their own, sharing common interests, act as host organizing discussions or events, that indispensable the daily lives of its audience, which makes people feel its lack, is not limited to communication based on price and product, but adding value for its service to the community through a positive attitude (eg Wikipedia - all around an interest free, everyone wants to contribute). The online presence and degree of interaction of the organizations should have four important factors as guidance on strategy for social media in particular, be found, to be true, be relevant and be promoted.

Be found by people looking for their products or services, enhancing the presence and content, under terms that are not filtered or refused to assume the position identification with the selected segment. The good companies are mainly aimed at meeting the needs of its customers, using the keywords and descriptions corresponding to the offer. To be authentic must demonstrate transparency and honesty, allow people to connect and identify with the company / brand. The very notion of community is related to the trust. Connect and commit the necessary help to create community around the business, own business / brand also helps define the people who take (reporting real stories). Companies must become part of the community in order to truly benefit from social media (regularly updated information, new routine messages, listen, respond, question, discuss, discuss, participate in daily life). Social media helps to feel part of a wider community [9]. 


\section{Conclusions}

Consumers are no longer passive, they are taking an active role in public and political communication, so organizations need to adopt a culture of inter- relational customers, based on trust and transparency.

There is a progression in the development of standards of transparency on-line. Consumers will manage and share their data with trading partners, making it a viable business model.

The major social players accumulate individualized information about each of their users in four groups of variables of marketing segmentation: demographic, geographic, psychographic and behavioral, in order to optimize the selection and provision of information customized to the individual profile, this customization can be extended to other areas of business and other businesses cut superfluous information received by consumers, which increase the efficiency and effectiveness of traditional marketing to social media.

New applications for the various social and mobile platforms will tend to a high customization, increasing the link between organizations and customers, this will provide increased communication effectiveness of on-line advertising with a social and interactive nature of the on-line marketing, viral and worth of mouth with a growing consumer participation in public and political communication.

\section{$5 \quad$ References}

[1] Armano, D. Responsive Marketing. 2013. Available: http://www.edelmandigital.com/ 2013/05/20/responsive-marketing. Last accessed 28 Jan 2015.

[2] Brenner, J. . Social Networking Sites. Pew Research Centre. 2013.

[3] Docherty, J. Changing perspectives in marketing. Glasgow Caledonian University. 2015.

[4] Garcia, I; Correia, P. The importance of social media for commerce. A case study in Madeira (Portugal). iJIM, Volume 6, Issue 1. 2012.

[5] Nuñez, A. Será mejor que lo cuentes. Spain: Empresa Activa. 2009.

[6] Okazaki, S. Social media and international advertising: theoretical challenges and future directions. (1), P56-70. 2013.

[7] O'reilly, T. What is Web 2.0. Available: http://www.oreilly.com/pub/a/web2/archive/whatis-web-20.html. 2005. Last accessed: 27 jan 27. 2015

[8] Scott, D. The new rules of marketing and PR, NY: John Wiley \& Sons, Inc.2010.

[9] Tapscott, D; Willian, A. Wikinomics: How mass collaboration changes everything. London: Atlantic Books. 2008.

[10] Tuten, T. (2012). Social media and the grocery Industry. East Carolina University.

[11] Zarrella , D. The Social Media Marketing Book. Canada. 2010.

\section{Authors}

Patrícia M. Farias Coelho is a PhD in Communication and Semiotics and Professor at the Interdisciplinary Master in Humanities Sciences in the. University of Santo Amaro - UNISA, Santo Amaro, Brasil 
Pedro A. P. Correia is PhD in Interactive Digital Communication and Marketing Professor at the University of Madeira, Funchal, Portugal.

Irene Garcia Medina is a Lecturer in Marketing, Business Management Department, Glasgow Caledonian University.

Article submitted 11 March 2017. Published as resubmitted by the authors 27 May 2017. 